\title{
Una necesaria aproximación a la responsabilidad penal por mala praxis médica
}

POR LIUVER CAMILO MOMBLANC $(*)$

\begin{abstract}
Sumario: I. Introducción.- II. La mala praxis médica: fundamento de la responsabilidad jurídico-penal.- III. Mala praxis médica: modalidades y sistemas de incriminación.- IV. La clasificación de la imprudencia en el análisis de la mala praxis médica.- $V$. Reflexiones finales.- VI. Bibliografía.
\end{abstract}

Resumen: las presentes reflexiones versan, desde un punto de vista peculiar sobre uno de los temas más polémicos y antiguos a lo largo de la historia de las ciencias jurídicas en su relación con el ejercicio de la medicina: la responsabilidad médica. Este tópico ha experimentado una especial preocupación en la sociedad contemporánea por la progresiva judicialización de la medicina. Mayor inquietud genera aquella que alcanza los predios del derecho penal en torno a la cual existe un creciente debate académico, siendo inevitable que surjan opiniones diversas en torno a la imprudencia médica. En el artículo se sistematizan, a partir de un estudio doctrinal, exegético y comparado, algunos de sus principales fundamentos teóricos. Nos referimos a los presupuestos de la responsabilidad jurídica, el concepto de

(*) Lic. en Derecho, Universidad de Oriente (UO). Lic. en Contabilidad y Finanzas, Universidad de Guantánamo (UG), Cuba. Esp. en Derecho Penal, UO. Esp. en Administración Pública, Escuela Superior de Cuadros del Estado y del Gobierno (ESCEG). Doctorando del Programa de Doctorado en Ciencias Jurídicas, UO, acreditado con la condición de Excelencia por la Junta de Acreditación Nacional de Cuba (JAN) y Mención de Honor de la Asociación Universitaria Iberoamericana de Posgrado (AUIP). Prof. Auxiliar de Derecho penal, Facultad de Derecho, Universidad de Oriente, Cuba. Prof. de Posgrado de la Especialidad en Derecho Penal, Universidad de Oriente, Cuba. Metodólogo de la Dirección de Organización Planificación y Archivo, Universidad de Oriente. Vicepresidente del Capítulo Provincial de Derecho penal de la Unión de Juristas en Santiago de Cuba. Orcid: https:// orcid.org/0000-0002-1311-095X 
mala praxis médica, las diferentes posturas relativas a su incriminación, así como a la relevancia de la clasificación de la imprudencia en el análisis de la mala praxis médica.

Palabras claves: imprudencia médica - responsabilidad penal médica - lex artis - imprudencia profesional

\section{A necessary approach to criminal liability for medical malpractice}

Abstract: the present reflections deal, from a peculiar point, with one of the most controversial and ancient themes throughout the history of legal sciences in their relation to the practice of medicine: medical liability. This topic has experienced special concern in contemporary society due to the progressive judicialization of medicine. The greatest concern is generated by medical liability in the field of criminal law. There is a growing academic debate on this subject and it is inevitable that various opinions will emerge on medical negligence. The article systematizes, from a doctrinal, exegetical and comparative study, some of its main theoretical foundations. We refer to the assumptions of legal responsibility, the concept of medical malpractice, the different positions regarding its incrimination, as well as the relevance of the classification of imprudence in the analysis of medical malpractice.

Keywords: medical negligence - medical criminal liability - lex artis - professional negligence

\section{Introducción}

La sociedad del presente está inexorablemente marcada por el riesgo constante en todas las esferas de la vida social, lo que es consecuencia directa de las formas de producción, difusión, transmisión y aplicación del conocimiento científicotecnológico. Este se torna incontrolable en muchas esferas porque los efectos que produce no son lineales y están condicionados por una dinámica que se mueve bajo los pares desarrollo-vulnerabilidad, progreso-inseguridad. En este escenario se permiten, consienten y auspician ciertas conductas que generan riesgo $-v . g r$. el tráfico automovilístico, el empleo de la energía nuclear con fines pacíficos-, en la medida en que los beneficios que generan son superiores a los perjuicios. Esta permisión del riesgo, entendido como la contingencia o proximidad de un daño, descansa en una valoración social de las conductas humanas que conduce a aceptar como normales y prudentes, acciones que en abstracto entrañan un peligro. Si no fuese así, si en todos los casos se exigiese obrar estrictamente sobre seguro, inevitablemente se obstaculizaría el avance científico.

De las repercusiones que esta necesaria e inevitable tecnificación de nuestro vivir ha tenido, con interés al derecho penal, destaca el incremento de la comisión 
de delitos imprudentes en ámbitos capaces de ocasionar grandes daños. Sin embargo, el trazo de los perfiles de la imprudencia como categoría dogmática hasta hace muy poco ocupaba un lugar secundario en la ciencia criminal, esencialmente desarrollada sobre la base de las conductas dolosas (Muñoz Conde y García Arán, 2010, p. 281; Palencia Núñez, 2017, p. 1; Roxin, 1997, p. 996). Esto exigió de esfuerzos doctrinales en la precisión del concepto y su ordenación sistemática en aras de resolver los problemas sociojurídicos que planteaba. No es por ello de extrañar que, en 1975, Schünemann manifestara que los delitos imprudentes habían pasado de hijastros a hijos predilectos de la dogmática jurídico penal (1975, p. 435).

Hoy se revela una nueva imagen de la imprudencia, afianzada en sus rasgos fundamentales, aunque los esfuerzos científicos que la desarrollan —-doctrinales, normativos, jurisprudenciales- no han producido aún tanto consenso y claridad como en la dogmática del delito doloso (Roxin, 1997, p. 997). Su desarrollo teóricopráctico responde a la necesidad que tiene la sociedad de establecer límites a la posibilidad de generar peligro para que la convivencia sea armónica. Con tales propósitos se auxilia del legislador que, como artesano de la ley, deja deslindado en disposiciones normativas el campo de riesgo que la sociedad acepta de aquel que corresponde al peligro que jurídicamente desaprueba (Terragni, 2001).

La actividad médica se puede invocar como uno de los sectores en los que el desarrollo científico técnico ha incidido especialmente en las últimas décadas. La necesidad de otorgar en este contexto una protección jurídica calificada a los bienes jurídicos en juego - en particular la vida y la salud psicofísica del pacienterequiere la imposición de reglas de cuidado para asegurar su correcto ejercicio. Es por ello que en su actuación profesional intervienen un grupo de reglas que intentan controlar y/o disminuir el riesgo inherente a la labor que realizan los galenos y que deben observar de cara a las exigencias concretas y específicas del caso clínico. De no ser así, podrían incurrir en una mala praxis con resultados de muerte o lesiones al paciente que de configurar los presupuestos de rigor conduciría a la exigibilidad de responsabilidad penal por imprudencia.

Las reflexiones que siguen pretenden sistematizar las diferentes posturas que en la actualidad se aprecian en torno al tratamiento teórico-normativo de la mala praxis médica, que configura como una actuación imprudente penalmente relevante. En este sentido, nos referimos a los presupuestos de la responsabilidad jurídica, el concepto de mala praxis médica, las diferentes posturas en torno a su incriminación, así como a la relevancia de la clasificación de la imprudencia en el análisis de la mala praxis médica. Para ello se desarrolla un estudio de carácter documental, utilizándose diferentes fuentes primarias y secundarias de información con la significativa aplicación del análisis exegético jurídico y la comparación jurídica como métodos particulares del Derecho. 


\section{La mala praxis médica: fundamento de la responsabilidad jurídico- penal}

El perfil del concepto de responsabilidad, además de depender internamente de la estructura de las normas de conducta, también depende de los fines y valores que persigue el sistema normativo que las ordena (De Larrañaga Monjaraz, 2015, pp. 1465-1469). En este sentido, puede hablarse, según la rama del derecho, de responsabilidad civil, penal, administrativa, laboral, calificadas por algunos autores como tipos, clases o modalidades (Koudriavtsev, 1988, pp. 17-18; De Larrañaga Monjaraz, 1996, pp. 11-17; Méndez López, 2009, p. 14). Obviamente, en cada uno de estos ámbitos del derecho, la responsabilidad jurídica y, consecuentemente, las construcciones dogmáticas que giran en torno a su imputación tienen características peculiares. Sin embargo, que existan diferentes tipos según el orden normativo en que opere el juicio de responsabilidad no impide que, en oportunidades, un mismo hecho contravenga más de una norma de conducta y genere diversas responsabilidades. En lo fundamental, las diferencias se asocian a cuatro elementos: a) el tipo de conducta que da lugar a la consecuencia normativa; b) el contenido de la consecuencia normativa; c) el procedimiento para determinar la adscripción de la consecuencia normativa y d) el objetivo de la imputación de dicha consecuencia (De Larrañaga Monjaraz, 2015, p. 1466).

Hart, al ocuparse del término responsabilidad, cuyas aportaciones lo convierten en uno de los autores más citados sobre el tema (Figueroa Rubio y Torres Ortega, 2018; De Larrañaga Monjaraz, 1996, pp. 31-105; Martínez Pérez y Alzate Peralta, 2019, p. 13; Méndez López, 2009, p. 9; Nino, 2003, pp. 184-186), subrayó que este concepto puede entenderse al menos en cuatro sentidos: 1) responsabilidad como obligación o funciones derivadas de cierto cargo, relación, papel o rol social (role-responsibility); 2) responsabilidad en el sentido de factor causal (causal-responsibility); 3) responsabilidad como capacidad o estado mental (capacity- responsibility) y 4) responsabilidad como sancionabilidad (liability-responsibility).

A la luz de su concepción, la "responsabilidad como sancionabilidad" se erige en concepto central que abarca la mayoría de los supuestos en los que aparece el término en los diferentes ámbitos normativos (De Larrañaga Monjaraz, 1996, p. 373; Méndez López, 2009, p. 10; Nino, 2003, p. 187). Molina Fernández, aunque lo denomina "responsabilidad como atribución de consecuencias por el hecho lesivo", también sostiene que es la noción más habitual de esta expresión en la ciencia jurídica; con ella se identifica quién o quiénes deben responder de un hecho, en el sentido de sufrir ciertas cargas que se anudan a su existencia (Molina Fernández, 2000, pp. 172-176).

Esto no significa limitar el término, como lo hace Kelsen, a la función de imputación de sanciones, pasando por alto los contextos en los que se vincula con 
la formulación de normas de conducta y la formulación de los criterios de imputación (De Larrañaga Monjaraz, 1996, pp. 368-370). A contrario sensu, bajo esta idea los restantes sentidos de responsabilidad constituyen —en distintas formas-presupuestos de los juicios de la responsabilidad como sancionabilidad. Así también opina Molina Fernández al referir que en la delimitación de las razones que justifican la imposición de consecuencias gravosas interesa también la intitulada por él "responsabilidad como originación", precisamente porque su concurrencia constituye el primero y más importante de esos criterios (Molina Fernández, 2000, pp. 171-178).

Conforme al esquema propuesto por Hart, la responsabilidad jurídica sigue la senda deber-antijuridicidad-responsabilidad (como se citó en Méndez López y Goite Pierre, 2012, p. 179). Visto en palabras de Vodanovic: "primero aparece el deber; después, sucesiva y condicionalmente al incumplimiento, la responsabilidad por no haber cumplido" (1995, p. 191). Una lógica elemental conecta las responsabilidades a los deberes pues, por ello, como asevera Valdez Díaz: "al deber jurídico le acompaña siempre la responsabilidad por su incumplimiento" (2005, p. 98). En consecuencia, en el sentido que aquí interesa, entendemos que "la responsabilidad no es sino un deber jurídico sucedáneo de un deber primario. Es la sujeción a la sanción contenida en la norma violada o la sujeción a los efectos reactivos del ordenamiento jurídico dimanante del incumplimiento de un deber anterior" (Vodanovic, 1995, p. 191).

A pesar de estas precisiones, frente a la compleja práctica de imputar responsabilidades - con mayor razón en el ámbito médico por la realidad contextual que entraña la propia praxis en este sector de actividad profesional- recurrimos a la propuesta de De Larrañaga Monjaraz. Este autor nos dice que la adopción de una sistemática de la responsabilidad es una buena estrategia para dar cuenta —-desde una doble dimensión normativa-descriptiva- de cómo se formulan y justifican los juicios de responsabilidad en el derecho. Toma como referente el concepto central de responsabilidad - la responsabilidad como sancionabilidad-y sostiene que se presenta como un sistema compuesto de tres tipos de enunciados normativos. Los enunciados son: 1) normas de conducta, 2) reglas de responsabilidad y 3 ) juicios de responsabilidad (De Larrañaga Monjaraz, 2015, p. 1460).

Bajo este modelo de comprensión, la noción de responsabilidad se relaciona con las normas de conducta - normas de mandato o de fin, que tienen como propósito dirigir las conductas-de dos formas distintas: a) de manera directa, como equivalente de obligación o de deber y b) de manera indirecta, como criterio de identificación de deberes especiales. Esta última noción es equivalente, en el esquema de Hart, a la responsabilidad como obligación o funciones derivadas de cierto cargo, relación, papel o rol social (role-responsibility). Aquí las reglas que 
atribuyen responsabilidades - reglas constitutivas o institutivas- presuponen otras normas de carácter secundario respecto del deber en cuestión. Así, cuando se dice que el médico es responsable del cuidado de la salud del paciente, aunque no se instituye una obligación o deber respecto de una conducta concreta, se hace referencia a la esfera de responsabilidades que deriva de la relación jurídica que este establece con el paciente. Esta esfera de responsabilidades se compone de todas las conductas concretas ligadas con las situaciones activas (modalidades) y situaciones pasivas (expectativas) correspondientes a dicho vínculo jurídico (Ferrajoli, 1997). De lo anterior deriva que la noción de responsabilidad en el ámbito médico conduce a la idea de la esfera de responsabilidad médica como criterio que engloba los deberes concretos relacionados con el ejercicio de la medicina (De Larrañaga Monjaraz, 2015, pp. 1460-1461).

Las reglas de responsabilidad - aquellas que establecen las condiciones necesarias para imputar sanciones en virtud del incumplimiento de la norma (conducta ilícita) - se refieren, fundamentalmente, a tres criterios de imputación: a) la capacidad de los sujetos normativos; b) la relación causal entre el sujeto y la conducta caracterizada por la norma de conducta; c) la relación entre el agente del ilícito y la persona a quien se dirige la sanción. Los dos primeros criterios se corresponden, en el esquema de Hart, con las nociones de la responsabilidad en el sentido de factor causal (causal-responsibility) y la responsabilidad como capacidad o estado mental (capacity-responsibility). Ahora bien, dependiendo del orden normativo - civil, penal, administrativo-y el sistema de responsabilidad específico que en este se asuma, la responsabilidad jurídica puede ser más o menos exigente en los criterios de imputación a los que liga sus consecuencias. En base a ello, el único requisito normativo imprescindible en el concepto de responsabilidad es el incumplimiento de un deber, denominado por De Larrañaga Monjaraz como criterio mínimo para la inteligibilidad de la noción de responsabilidad (De Larrañaga Monjaraz, 2015, pp. 1461-1463).

Finalmente, "un juicio de responsabilidad es el resultado de subsumir una conducta en un sistema de responsabilidad" (De Larrañaga Monjaraz, 2015, p. 1463) que se compone de una norma de conducta y las reglas de responsabilidad que establecen las condiciones normativas necesarias - criterios de responsabilidadpara que pueda imputarse una sanción. En este sentido, será correcto el juicio si dicha subsunción satisface las reglas de responsabilidad que establece el sistema normativo en relación con la norma de conducta de que se trate. Un juicio de responsabilidad puede rechazarse negando cualquiera de sus elementos, esto es, a) negando el hecho particular - acción o estado de cosas- que se imputa al sujeto; b) afirmando que la norma de conducta no es aplicable al caso, o bien, c) afirmando que, aunque el hecho que se imputa y la norma es aplicable al caso, no se satisface alguna regla de responsabilidad (De Larrañaga Monjaraz, 2015, p. 1464). 
En el sector de la salud, el acto médico presupone una obligación legal que se origina de la interacción médico-paciente. En ese momento nace la relación jurídico-médica y con ella el reconocimiento de los derechos y obligaciones de los sujetos que la configuran. Cuando en el marco de este vínculo jurídico se incumple un deber, se produce un acto médico contrario al ordenamiento médicolegal, se genera, en principio, la responsabilidad médica como sancionabilidad. Su concreción dependerá de la satisfacción de las "reglas de responsabilidad" y el resultado del "juicio de responsabilidad" conforme al orden normativo en el que tengan lugar.

Sin embargo, no es ocioso señalar que los trabajadores de la salud pueden incurrir en responsabilidad jurídica tanto en el marco de la relación médico-paciente como fuera de ella. Asimismo, la responsabilidad médica se origina no solo durante la ejecución del acto médico, pues puede surgir luego de haberse concluido la terapéutica planificada y puede estar asociada, v.gr., al secreto profesional. En cualquier caso, tendrá su génesis en el incumplimiento de un deber relativo a la esfera de responsabilidades correspondiente al servicio de la salud que se presta, lo cual se relaciona con la noción de responsabilidad como obligación o funciones derivadas de cierto cargo, relación, papel o rol social expuesta por Hart.

De las diferentes situaciones que generan responsabilidad médica, objeto de nuestro estudio es la mala praxis que en la literatura científica también encontramos con la denominación de "mala práctica," “mulpractice”, "mulpractique”, "kunstiehler", "malpractice", "malpraxis", "falta médica", "tratamiento contra legis artis". La misma se define como la acción de dañar total o parcialmente, temporal o de manera permanente la salud humana en el marco de la relación médico-paciente, resultado de un acto médico imprudente. En estos casos, el daño ha sido provocado porque la actuación médica se aparta del deber de cuidado que exige el caso concreto, haciéndose merecedora de la tacha de la imprudencia. Es la responsabilidad médica stricto sensu o responsabilidad médica propiamente dicha, calificada también como una variedad de la responsabilidad profesional, razón por la cual se significa su naturaleza culposa (cometida sin la intención de hacer daño).

La literatura científica, sobre todo la literatura médico-legal (Amores Agulla y Marrero Quesada, 2015; David Tole y Cadavid, 2018; Dossier: Mala praxis médica. Selección de jurisprudencia y doctrina, 2018; Gamboa Montejano y Valdés Robledo, 2015, p. 77; Guzmán Mejía, 2018; Organización Panamericana de la Salud, 2004, p. 48; Vargas Alvarado, 2012, p. 498; Vila Morales y Pérez Echeverría, 2013, p. 191), se refiere con frecuencia a la mala praxis como la actuación por imprudencia, negligencia, impericia o inobservancia de los reglamentos y deberes exigidos a los profesionales de la salud durante la realización del acto médico. Sin embargo, en rigor, estos términos son reconducibles recíprocamente y tal distinción suma 
dificultades para su identificación en un caso concreto en el que pueden verse entremezcladas, tratándose, en definitiva, de una conducta imprudente en sentido amplio.

Es importante destacar que solo el personal técnico-profesional de las ciencias de la salud es competente para efectuar actos médicos. Solo ellos, dentro de los trabajadores del sector, se encuentran habilitados por las autoridades pertinentes para el ejercicio de la profesión según lo dispuesto por las normas jurídicas correspondientes. De ahí que, en un primer momento, resulte presumible la noción de responsabilidad como capacidad que planteara Hart y definiera De Larrañaga Monjaraz al referirse a las reglas de responsabilidad, cuya ausencia imposibilita la tipificación de la mala praxis. También debemos señalar que, al producirse el daño a la salud o la vida en el marco de un acto médico, debe demostrarse que estos resultados no fueron consecuencia de complicaciones propias del proceder o por mala evolución o capacidad reducida de recuperación del paciente. Esto es así porque la relevancia —-sobre todo en el orden jurídico penal o civil- de la mala praxis médica depende de estos resultados. De ahí su necesaria diferenciación de otras situaciones o eventos en los cuales - también en el marco del acto médico- se producen esos resultados y no le deben ser imputados al profesional de la salud. Así, $v$.gr, en caso de eventos adversos que clasifican como iatrogenia, error médico (invencible) o complicaciones médicas.

Como nuestro objeto de directa atención es la responsabilidad penal por mala praxis médica frente a los eventuales resultados de muerte o lesiones al paciente, resulta necesario hacer una breve referencia a los criterios que en este ámbito justifican su imputación. En este sentido, como punto de partida, asumimos que: “(...) la responsabilidad jurídico-penal consiste en la obligación que tiene un sujeto imputable de sufrir las consecuencias legalmente instituidas (las sanciones o penas), por la perpetración de un hecho socialmente peligroso y antijurídico también previsto en la ley (los delitos)" (Quirós Pírez, 2002, p. 3). De conformidad con esta definición - aun cuando opinamos que el término más adecuado sería el de sujeto culpable en lugar de imputable-(1) la responsabilidad en sede penal se origina en el momento en que se comete un hecho delictivo, dando lugar a una relación jurídica entre el Estado y el agente comisor. Sustentado en dicha relación, el primero se encuentra legitimado para imponer la sanción correspondiente y el infractor tiene la obligación de sufrir las consecuencias jurídico penales del acto delictivo realizado. De esta forma se verifica que la responsabilidad jurídica se estructura a partir de una relación jurídica, razón por la cual también se coincide con

(1) La imputabilidad es condición necesaria pero no suficiente para responder de un delito. Vencido el juicio de la antijuridicidad, la imputabilidad constituye solo uno de los presupuestos del juicio de culpabilidad que no bastaría para la realización de la imputación subjetiva completa. 
Méndez López cuando define la responsabilidad penal en sentido general "como aquella que se origina ante la vulneración del deber de abstención de no cometer delitos, que implica la sujeción de quien quebrantó dicho deber de la obligación de sufrir una pena y soportar otras consecuencias" (Méndez López, 2009, p. 19).

Al hilo de lo indicado, la determinación de la responsabilidad penal remite al examen de aspectos teóricos de viva polémica en el derecho penal, como los relacionados con la teoría del delito, la cual ofrece un esquema metodológico que permite establecer si una determinada conducta genera responsabilidad penal (Bustos Ramírez y Hormazábal Malarée, 1997, p. 127; Muñoz Conde y García Arán, 2010, p. 201; Roxin, 1997, p. 196; Zaffaroni, Alagia y Slokar, 2005, p. 292). A pesar de las divergencias teóricas, "en la moderna dogmática del Derecho penal existe en lo sustancial acuerdo en cuanto a que toda conducta punible supone una acción típica, antijurídica, culpable y que cumple otros eventuales presupuestos de punibilidad" (Roxin, 1997, pp. 193-194). No obstante, como también advierte Roxin, el contenido concreto de cada una de ellos y su relación recíproca son discutidos según los distintos puntos de vista científicos de que se parta, presentando aspectos diferentes para cada uno (Roxin, 1997, p. 194). Luego, retomando la propuesta de De Larrañaga Monjaraz, sostenemos que el reparto de las "reglas de responsabilidad" entre estos elementos refleja el reconocimiento de diferentes niveles de imputación.

En este sentido, Molina Fernández reconoce al menos cuatro niveles jerárquicamente ordenados que - asociados a las categorías de la teoría del delito- permiten justificar la imposición de responsabilidad jurídica en sede penal. En primer lugar, la causalidad de la acción humana, entendida, en un sentido exclusivamente científico, como vinculación conforme a leyes naturales; en segundo lugar, la imputación objetiva, como vínculo normativo en el que se atiende a si el resultado es, además de causado, la concreción del peligro jurídicamente desaprobado que encierra la acción o si esta es la frustración de una expectativa social fijada en un rol; en tercer lugar, el hecho objetivamente imputable debe ser, además, efecto del dolo - natural, referido al hecho, pero no al conocimiento de la antijuridicidaddel autor que se erige en elemento central del tipo subjetivo o la infracción del deber de cuidado; por último, al vínculo de tipicidad objetivo-subjetiva se suman el resto de los elementos de la imputación subjetiva examinados en la culpabilidad, lo que permite afirmar la presencia de un vínculo de imputación completo (Molina Fernández, 2000, p. 174).

\section{Mala praxis médica: modalidades y sistemas de incriminación}

Una mirada desde la perspectiva del derecho comparado hacia la mala praxis médica, entendida como imprudencia profesional o simplemente imprudencia 
médica penalmente relevante, deja ver las generalidades y tendencias sobre su regulación penal. En esta dirección, se aprecian diferentes enfoques normativos inspirados en las voces doctrinales que lo avalan, en la jurisprudencia, y también inspiradores de estas. Como explica Gómez Rivero, "a diferencia de lo que sucede en otros sectores de actividades de riesgo en los que son mínimas las dificultades para traducir desde un punto de vista político criminal de oportunidad el juicio de reproche al que conduce un análisis estrictamente dogmático, la realidad contextual en la que se desenvuelve la praxis médica propicia toda una escala valorativa a la hora de traducir en términos penales el comportamiento imprudente" (2003, p. 327).

El espectro de reacciones oscila desde quienes propugnan un trato menos severo ante los resultados lesivos ocasionados por imprudencia en el ejercicio profesional hasta aquellos que reclaman especiales niveles de exigencia. Concretamente, asociado a la actividad médica, los defensores de medir conforme a rígidos baremos la imprudencia del profesional de la salud fundamentan su postura en el singular valor de los bienes jurídicos que pueden resultar lesionados. Para ellos, en este ámbito han de extremarse las medidas de cuidado, de tal forma que, en principio, cualquier descuido de las mismas podría dar paso a la responsabilidad (Gómez Rivero, 2003, p. 328). También encontramos quienes, en términos generales, la basan en un mayor desvalor de acción, en un "plus de antijuridicidad" (Córdoba Roda, 1996, p. 146; Gratascós Gómez, 1997, p. 74; Núñez Barbero, 1975, p. 93), en razones de política criminal (Romeo Casabona, 2005, p. 21) o atendiendo a la teoría de los fines de la pena, tanto en su vertiente preventivo-general como preventivo-especial (Rodríguez Vázquez, 2012, p. 68; De Vicente Remesal y Rodríguez Vázquez, 2007, p. 156).

Los que se oponen a esta forma de pensar sostienen que el juicio de reproche por imprudencia debe ceñirse a los casos en los que la misma revista especial gravedad sobre la base de diferentes razones. Entre ellas, la especial proclividad con que es posible apreciar en este ámbito una actuación imprudente debido a la incerteza de la ciencia médica. Asimismo, la premisa humana de impedir que el médico realice su actividad presionado por el temor de acabar ante los tribunales, con los riesgos que ello implica asociados a la medicina defensiva frente a la efectiva atención y cuidado del paciente (Gómez Rivero, 2003, p. 328). Otros entienden que la imprudencia profesional carece de un perfil intrínseco que la distinga de la imprudencia común o genérica, razón por la cual reclaman su desaparición de aquellas disposiciones legales que la estipulan a través de figuras o cláusulas especiales (Cadavid Quintero, 1998, p. 92; Fernández Hierro, 1997, p. 463; García Andrade, 1998, p. 18; Silva Sánchez, 1999, p. 24; Villacampa Estiarte, 2003, p. 124).

Sobre esta base, la revisión de una selección de códigos penales permitió distinguir la forma en que desde el derecho positivo en la actualidad se encara la 
responsabilidad penal por imprudencia profesional en general y la médica en particular(2). De acuerdo con la exploración de la legislación, la primera cuestión interesante es la adopción - como tendencia- del sistema de numerus clausus o crimina culposa en la incriminación de la actuación imprudente. En casi la totalidad de las legislaciones estudiadas ( $15-93.75 \%$ - de 16) solo podrá apreciarse la imprudencia en aquellos supuestos en los que expresamente se contemple en algún precepto de la parte especial del Código Penal(3). Ello sucede, sobre todo, en la lesión y puesta en peligro de la integridad física y la vida, o sea, en el homicidio y las lesiones. Bajo esta órbita se aprecia una adecuada consagración a los principios de ultima ratio y carácter fragmentario de derecho penal asociada a la concepción de la conducta imprudente con significación penal.

El escenario cambia frente a la búsqueda de cláusulas o figuras que distingan la imprudencia común de la profesional o mala praxis. En este sentido, en plena coherencia con lo subrayado supra en el orden doctrinal, se identifican distintas posiciones normativas. De acuerdo con este estudio, se identificaron legislaciones que se insertan en las filas de quienes propugnan reaccionar de forma más enérgica frente a la imprudencia profesional que frente a la genérica $(8-50 \%-$ de 16) (4). En el extremo opuesto, o sea, aquellas que prescriben una especial condescendencia, encontramos solo una entre las estudiadas $(1-6.255 \%-$ de 16$)(5)$. También identificamos siete códigos que no contemplan preceptos especiales, lo que no significa que son indiferentes o no reflejan una forma de valorar la imprudencia profesional ( $7-43.75 \%$ - de 16)(6). En estos casos —al decir de Gómez Rivero-, la postura que se deja ver es la de medirla conforme a reglas generales, porque todos los códigos penales son expresión de una carga ideológica determinada. Así, de forma implícita, se manifiesta en ellos que el profesional ni merece mayor condescendencia ni un trato más severo, relegando a la labor de los tribunales la cuantificación de la gravedad de su actuación según el caso concreto (Gómez Rivero, 2003, p. 329).

Otros de los aspectos objeto de indagación versó en torno a la previsión para estos casos de la pena de "inhabilitación profesional" y su naturaleza. Habida cuenta que su imposición —según sostiene Hava García - deja marginado al profesional

(2) Fueron seleccionados los códigos penales de Chile, México, Colombia, Argentina, Costa Rica, Perú, Paraguay, Bolivia, Uruguay, Ecuador, El Salvador, Venezuela, España, Alemania, Francia e Italia.

(3) Solo el Código Penal de Distrito Federal de México mantiene el sistema de numerus apertus en relación a la imprudencia.

(4) Son los códigos penales de España, Chile, México, El Salvador, Argentina, Perú, Bolivia e Italia.

(5) Se trata del Código Orgánico Integral Penal de Ecuador (COIP).

(6) Son los códigos penales de Alemania, Francia, Colombia, Costa Rica, Paraguay, Venezuela y Uruguay. 
del campo laboral en el ejercicio de su profesión, resulta especialmente gravosa (Hava García, 2001, p. 32) y ha generado, sobre todo en España, una especial polémica. De su análisis apreciamos que su fijación constituye una tendencia en los códigos penales estudiados, ya sea como sanción accesoria o principal. También se prevé con carácter preceptivo en aquellos ordenamientos que distinguen la imprudencia profesional e incluso en los que no lo hacen. Del tenor literal de las normas que la estipulan se revela como fundamento la necesidad de su exigencia debido a que en estos casos el resultado de muerte o lesiones obedece a la inobservancia de los deberes ligados al ejercicio de la profesión.

En un segundo momento del estudio comparado escudriñamos en la experiencia española y ecuatoriana para conocer el debate doctrinal y jurisprudencial que se ha generado en torno a la postura asumida en su legislación porque cada una de estas legislaciones representa los dos extremos de los sistemas acogidos para la exigencia de la responsabilidad por mala praxis médica. A partir de la configuración típica de la imprudencia profesional en España, se advierte una mayor incriminación de la imprudencia relativa al ejercicio de la medicina mediante la incorporación, con la adopción de la ley orgánica 10/1995 de 23 de noviembre, de conductas que antes quedaban al margen de un tratamiento claramente agravatorio e incluso de la esfera de lo típico (Gómez Rivero, 2003, p. 330; Hava García, 2002, p. 31; Rodríguez Vázquez, 2012, p. 64).

La mayor preocupación, no obstante, está asociada a que el legislador español no especifica - como tampoco lo hace ninguno de los códigos estudiados- qué entender por imprudencia profesional. Deja al arbitrio del operador jurídico la delimitación de los contornos por vía de interpretación de una figura cuya aplicación implica una agravación punitiva. Frente a esta situación, y en aras de argumentar la adopción de una cláusula normativa para la imprudencia profesional, el Tribunal Supremo intentó establecer criterios materiales con los que superar el carácter objetivo de evaluación de la responsabilidad toda vez que se atribuye una mayor pena a un sujeto a tenor de su cualidad personal.

En este tenor se acuñan por vía jurisprudencial los conceptos "imprudencia del profesional" e "imprudencia profesional" (Rodríguez Vázquez, 2012, p. 65; Vallejo Jiménez, 2012, pp. 104-105; De Vicente Remesal y Rodríguez Vázquez, 2007, pp. 158-159). La primera se define como aquella cometida por una persona en el ejercicio de su profesión, pero por infracción de normas de cuidado comunes, esto es, que no son propias del ejercicio profesional. Constituye una imprudencia común pues podría haber sido cometida por cualquiera. A contrario sensu, la segunda tendría lugar cuando el profesional infringe normas técnicas, propia de su 
esfera de actuación, que tenía el deber de conocer y aplicar, pero para el profano resultarían de imposible cumplimiento (Rodríguez Vázquez, 2012, p. 65) (7).

De cualquier forma, pese a los esfuerzos de la jurisprudencia española, en su praxis judicial existen fallos contradictorios e imprecisos que dejan serias dudas acerca de cuáles son las fronteras entre ellas (Rodríguez Vázquez, 2012, p. 66; Vallejo Jiménez, 2012, pp. 111-123; Villacampa Estiarte, 2003, p. 121). Ello es comprensible que suceda si tenemos en cuenta que el primer imponderable se presenta a la hora de diferenciar entre "normas de cuidado comunes" y "normas de cuidado propias de la profesión". En este sentido - como dice Rodríguez Vázquez-, cabe cuestionarse si existen acciones ejecutadas en el marco del ejercicio profesional que no estén regidas también por normas de cuidado profesionales, aunque puedan encontrar su réplica en actividades comunes (extraprofesionales) del hombre (Rodríguez Vázquez, 2012, p. 66). Además, conforme advierte Cerezo Mir, en el caso de actividades que pueden desarrollar tanto profesionales como no profesionales $-v$.gr. la conducción de vehículos de motor-, carecerían de justificación normas especiales de cuidado exigibles solo a los primeros para la protección de los bienes jurídicos en riesgo. De modo que no cabría hablar en su caso de un "plus de injusto", porque el cuidado objetivo que hayan infringido será exactamente el mismo que infrinjan los no profesionales: el necesario. De la misma forma, en las actividades que solo ellos pueden realizar, la infracción del deber objetivo de cuidado se concreta siempre en la infracción de las reglas técnicas que deben observar. Mas, como el cuidado definido por dichas reglas no puede ser otro que el necesario, no cabe ver tampoco en la infracción de las mismas ningún "plus de injusto" que justifique la agravación (como se citó en Díez Ripolles, Gracia Martín, y Laurenzo Copello, 1997, p. 157).

Estos mismos argumentos resultan válidos para desestimar las opiniones que sostienen la necesidad de la distinción y el mayor reproche penal que de ella deriva, en un mayor desvalor de la acción. El elemento decisivo de lo injusto en los delitos imprudentes es siempre la infracción de unas reglas de comportamiento correspondientes al sector de tráfico jurídico en el que se despliegue la actuación (Roxin, 1997, p. 1003; Welzel, 2004, pp. 113-119). Su contenido se determina, en principio, atendiendo al hombre medio ideal situado en la posición del concreto sujeto que realice la acción. En efecto, el dato de la actividad profesional es relevante para establecer si se ha producido la infracción al deber de cuidado, mas no para sobrevalorar la conducta e imponer un mayor grado de injusto en el

(7) Véanse también: Sentencia Juzgado de lo Penal Provincia de Málaga, No 351/2014; Sentencia No 307/2006 de TS, Sala 2a, de lo Penal, 13 de Marzo de 2006; Sentencia No 805/2017 (Roj: STS 4867/2017 - ECLI: ES: TS: 2017:4867). En la misma línea resulta ilustrativa la STS de 8 de junio de 1994, citada en Sanz Mulas, 2014, p. 322. 
comportamiento del infractor (García Rivas, 1999, p. 95). El desvalor de la acción es, sin duda, un elemento esencial del delito imprudente, pero resulta insuficiente para justificar la fijación de una circunstancia de agravación punitiva solo para los profesionales. Tan disvalioso es la infracción del deber de cuidado, que produce una lesión al bien jurídico que se intenta proteger a través de la figura del delito imprudente si la realiza un profesional como quien no ostenta tal condición.

Hava García y De Vicente Remesal argumentan el establecimiento de la elevación penológica en criterios preventivos especiales (Hava García, 2001, p. 36; De Vicente Remesal, 2000, p. 106). Consideran que quien en el ejercicio de su profesión comete una imprudencia grave revela su incapacidad para controlar el foco de peligro que a diario abraza la actividad que realiza y tal peligrosidad debe ser neutralizada. En base a ello, lo pertinente será apartar a esta persona de esa actividad a través de una sanción que lo inhabilite para ejercer por un período de tiempo determinado. Así, procuran justificar la adición de la inhabilitación especial para la imprudencia profesional que realiza el legislador del Código Penal español de 1995 en lugar de la fijación de la sanción acercándose al límite máximo del marco penal previsto para el delito (Rodríguez Vázquez, 2012, p. 67; Vallejo Jiménez, 2012, p. 129).

Una posición distinta asume Vallejo Jiménez, a quien, si bien le parece razonable que una sanción como la inhabilitación en el ejercicio profesional pueda tener efectos de prevención, considera que para tales fines es suficiente la pena privativa de la libertad. Por tanto, resulta superflua la agravación con la única justificación de servir como sanción ejemplificante, así como para evitar que el profesional que ha sido inhabilitado repita actuaciones tan gravemente descuidadas (Vallejo Jiménez, 2012, p. 131). Lo cierto es que - como apunta esa propia autora - "ni en la doctrina, ni mucho menos en la jurisprudencia, existen razones lo suficientemente sólidas que permitan justificar la existencia de la agravación de la responsabilidad penal por imprudencia profesional" (Vallejo Jiménez, 2012, p. 129). Incluso, de considerar en alguna medida válidos los argumentos que se esgrimen a favor de la agravación, solo se justifica la mayor reprochabilidad de la inobservancia del deber de cuidado dentro del marco penal abstracto fijado por la ley.

En ese mismo orden, la pena de inhabilitación del ejercicio de la profesión, aunque se fundamente en criterios de prevención, debe ser de naturaleza facultativa. Además, en estos casos, como opinan De Vicente Remesal y Rodríguez Vázquez, no debe consistir necesariamente en una prohibición total o general del ejercicio de la medicina, sino restringirse al ámbito concreto en el que se cometió el hecho delictivo. Así, v.gr., prohibición del ejercicio de la ginecología pero no de ser colaborador de otro médico con el cual se puede trabajar bajo supervisión $o$ control (De Vicente Remesal y Rodríguez Vázquez, 2007, p. 156). 
En el caso de Ecuador, a partir de la puesta en vigor el 10 de agosto de 2014 del Código Orgánico Integral Penal de Ecuador (COIP), se tipifica el "Homicidio culposo por mala práctica profesional” (República de Ecuador, Asamblea Nacional, 2014)(8). De esta forma, se desarrolla normativamente un tipo específico sobre la responsabilidad profesional que ya había sido prevista en la Constitución del 2008 (9). Sin embargo, la incorporación de esta figura no significa que con ella se viniera a colmar un vacío legislativo generador de impunidad frente a resultados de muerte o lesiones ocasionados por mala práctica o imprudencia profesional. Antes, bajo el Código Penal de 1971, estos supuestos encontraban respuesta en los tipos penales del "homicidio inintencional" y las "lesiones inintencionales"; solo que esta vez el homicidio culposo por mala práctica profesional es un delito especial impropio: tiene por base el delito de "homicidio culposo" (artículo 145 COIP) simple y se constituye en una modalidad autónoma que requiere como sujeto activo un profesional en la práctica de sus funciones.

Para su tipificación, el legislador exige el reconocimiento de la necesaria infracción a un deber objetivo de cuidado, deja claro que la mera producción del resultado no lo configura y que debe haberse inobservado leyes, reglamentos, ordenanzas, reglas técnicas o lex artis aplicables. También tendrá que existir relación directa entre infracción y resultado, analizándose el grado de formación profesional, las condiciones objetivas, la previsibilidad y la evitabilidad del hecho (artículo 146 COIP). En fin, establece en el propio precepto penal un conjunto de pautas normativas para la determinación de la infracción al deber objetivo de cuidado. Sin embargo, llama la atención que se asigna un rango de pena menor a esta figura (uno a tres años) que al homicidio culposo (tres a cinco años). Visto así, es más grave que una persona común provoque la muerte por imprudencia que un médico u otro profesional lo haga en el ejercicio o práctica de su profesión. En razón a ello lo ubicamos como la legislación que adopta una postura hacia un tratamiento privilegiado de la imprudencia profesional. Solo cuando el homicidio culposo por mala práctica profesional se produce por acciones innecesarias, peligrosas e ilegítimas, se integra la modalidad agravada (tres a cinco años) que incluso contiene el mismo marco penal abstracto del homicidio culposo.

(8) Artículo 146 del COIP: "La persona que al infringir un deber objetivo de cuidado, en el ejercicio o práctica de su profesión, ocasione la muerte de otra, será sancionada con pena privativa de libertad de uno a tres años". Esta formulación legal también es utilizada para imputar los casos de infracción al deber de cuidado con resultado material de lesiones, por remisión expresa que a ella hace el artículo 152.

(9) Artículo 54 de la Constitución de la República de Ecuador: “Las personas serán responsables por la mala práctica en el ejercicio de su profesión, arte u oficio, en especial aquella que ponga en riesgo la integridad o la vida de las personas" y, en el artículo 75, garantiza a toda persona el acceso a la justicia y el derecho a la tutela efectiva, imparcial y expedita de sus derechos e intereses. 
Como se aprecia, es obvia la diferenciación entre la imprudencia común u homicidio culposo y la imprudencia profesional que intitula homicidio culposo por mala práctica profesional. Sin embargo, amén de que este precepto pueda haberse inspirado sobre todo en la mala praxis médica, no podemos decir que de forma expresa se distinga en él la imprudencia de estos profesionales en particular. Ha sido el Ministerio de Salud de ese país quien, al decir de Palencia Núñez, ha salido a la palestra de la discusión a dar la interpretación desde el sector público oficial del texto sobre homicidio culposo por mala práctica (Palencia Núñez, 2017, p. 108). Ello porque su concreción legislativa en sede penal como figura específica generó un amplio debate, especialmente entre los profesionales de este sector, cuyos gremios sostienen que con ello se criminaliza su labor.

A la vista de lo anterior, el citado órgano comunicó que por ningún motivo el ordenamiento penal pone en riesgo el ejercicio profesional. Aseguró que la elaboración de esta figura penal fue ampliamente trabajada, discutida y consensuada alcanzándose un texto equilibrado que, por un lado, acoge las necesidades de los ciudadanos y a la vez ampara a los médicos en el ejercicio de su profesión (Ministerio de Salud Pública del Ecuador, s./f.). Lo cierto es que la sola creación de esta figura autónoma, aunque con una pena menor que la del homicidio simple en su figura básica e igual a este en la agravada, ha sido captada como una forma de criminalización de la actividad médica. Digamos que, en la práctica, la creación de una figura independiente impropia de la imprudencia profesional, a pesar de que se le establezcan las mismas penas que al homicidio simple e incluso menor que este, ha tenido un efecto incriminatorio. Así se puede entender si evaluamos que en entrevista realizada el martes 4 de junio de 2019 por la Reacción Médica de Quito a Paúl Franco, director del Área Procesal de DS Legal Ecuador, el mismo manifestó que a lo largo de toda la historia se han registrado cerca de 50 denuncias a médicos en ese país y más o menos en un rango de cerca de cuatro años (desde la adopción del COIP hasta diciembre del año 2018) se han producido 577 (Franco, 2019).

En síntesis, a la vista de lo apuntado, se advierte una inclinación de los sistemas punitivos hacia la distinción de la imprudencia profesional en relación a la imprudencia común. Tal proceder, que se justifica desde el punto de vista teórico en función de su mejor estudio y comprensión, resulta inaceptable en el plano normativo en tanto suponga una desviación del principio de igualdad por ausencia de un debido elemento de relevancia para efectuar el distingo; sobre todo en aquellos casos en que el énfasis se hace hacia la profesión médica. De así considerarlo - criterio que rechazamos - se debería exigir para la infinita gama de profesiones creadoras de riesgos asociados a la vida y salud de las personas (Martínez Lazcano, 2011, p. 235; Perin, 2018, p. 879). También, de este análisis se revela que la categoría de la imprudencia profesional en las legislaciones penales no añade nada, al 
contrario, distorsiona el sistema de penas y es difícil de defender. Es bien complejo determinar dónde está el mayor desvalor de acción y, por tanto, de injusto, en estos casos que justifique una mayor conminación penal abstracta. Al menos desde el punto de vista normativo creemos que esta sería una categoría prescindible.

La práctica ha demostrado que una mayor intervención y severidad del derecho penal en el ámbito médico como mecanismo de tutela a los bienes jurídicos en juego no es el paradigma más eficiente (Perin, 2018, p. 889; Romeo Casabona, 2007, p. 251). Su creciente utilización, fundamentada en cuestiones de política criminal no bien formuladas, resulta en una alteración de las estructuras de comportamiento de los profesionales de la salud partícipes del conflicto penal, que, a la postre, conlleva una afectación a los bienes jurídicos que se procuran tutelar. Así lo revelan las preocupaciones que genera el recurrente problema de la llamada "medicina defensiva". Ante esta situación, la búsqueda de un modelo eficiente resulta justificable. Un esquema que permita conjugar de mejor manera, por un lado, el principio de responsabilidad y, por otro, la implementación de las mejores condiciones para el ejercicio de la actividad médica y la protección de los bienes jurídicos involucrados. Un diseño favorecedor del equilibrio entre ambos extremos de la relación-médico paciente.

\section{La clasificación de la imprudencia en el análisis de la mala praxis médica}

En la literatura penal existe consenso al clasificar la imprudencia, "según el contenido psicológico de la acción imprudente" (Mir Puig, 2016, p. 294), en consciente o con representación e inconsciente o sin representación. En la primera, el sujeto se representa la posibilidad de producción del resultado, es decir, tiene consciencia de que el resultado típico puede sobrevenir a partir de la creación del peligro por él generado. En la segunda, pese a tener los conocimientos que le permitirían representarse esa posibilidad de producción del resultado, no piensa en ello y, por ende, no se la representa o, lo que es lo mismo, no tiene consciencia de la creación del peligro, que siempre es de un resultado (Jescheck y Weigend, 2002, p. 611; Mir Puig, 2016, p. 294; Zaffaroni y otros, 2005, p. 425).

Esta distinción, sin embargo, no posee gran relevancia normativa, porque el legislador nunca vincula a ellas diferentes consecuencias jurídicas (Mir Puig, 2016, p. 294; Muñoz Conde y García Arán, 2010, p. 288; Roxin, 1997, p. 1019; Zaffaroni et al., 2005, p. 425). En cambio, las distintas figuras que Roxin califica como "formas más fuertes y más débiles" (1997, p. 1024) encuentran, por lo general, anclaje normativo en las legislaciones penales. Así, $v$.gr., cuando en la construcción de los tipos imprudentes se usan los términos "imprudencia temeraria o grave, menos grave, simple o leve". También cuando sobre esa base no se hace "en numerosos casos presupuesto de la punibilidad la mera imprudencia simple, sino sólo una 
forma cualificada" (Roxin, 1997, p. 1024). De igual modo cuando son usadas como fundamento para distinguir entre delito y falta en plena simetría a los principios limitativos del ius puniendi, especialmente de ultima ratio y el de insignificancia (Martínez Lazcano, 2011, p. 236; Terragni, 2003, p. 28; De Vicente Remesal y Rodríguez Vázquez, 2007, p. 152). No es por ello de extrañar que tanto la doctrina como la jurisprudencia se ocupen de esta clasificación, la cual fundamentan en la gravedad de la infracción de la norma de cuidado como criterio normativo (Mir Puig, 2016, p. 295).

La gravedad de la culpa - en cuanto al contenido de injusto- la señala su temeridad, que califica como una imprudencia grave, burda, sustancialmente elevada, que tiene lugar cuando hay dominabilidad (Roxin, 1997, p. 1024; Zaffaroni y otros, 2005, pp. 392-425) y se omiten las más elementales normas de cuidado o la que no cometería el hombre menos cuidadoso o diligente (De Vicente Remesal y Rodríguez Vázquez, 2007, p. 153). Es aquella que supone una "grave negligencia, imprevisión o descuido que, con olvido o desprecio de elementales precauciones, ocasiona un hecho castigado como delito cuando se realiza con dolo" (Martínez de Navarrete, 1995, p. 233).

Según Ruíz Vadillo, hay imprudencia grave cuando quien "actuando con olvido de los más elementales criterios de prudencia; es decir, de sensatez y equilibrio, haciendo caso omiso de los deberes de cuidado que ha de observar, atendidas las circunstancias de tiempo, de lugar, de situaciones y de personas, ejecuta un hecho que de mediar dolo, constituiría delito" (1994, p. 509).

Frente a esta, la imprudencia insignificante o levísima supone pequeñas faltas de atención cuya existencia ocasional no siempre es evitable ni siquiera para una persona concienzuda o escrupulosa (Roxin, 1997, p. 1028). Se configura frente a una falta de atención de poca entidad a las normas de cuidado o de una desatención a normas de poca entidad (De Vicente Remesal y Rodríguez Vázquez, 2007, p. 153). En palabras de Gómez Rivero, es "aquella en que puede incurrir cualquier persona normal, esto es, la que por contraposición a la anterior, sería propia de una persona no gravemente descuidada" (Gómez Rivero, 2003, p. 374). En estos casos - como apunta Roxin - "no resulta adecuada una pena criminal, porque una culpabilidad que alcanza a cualquiera no puede ser combatida eficazmente mediante ella; basta con la compensación jurídico civil de las consecuencias del daño" (Roxin, 1997, p. 1028).

En cualquier caso, es forzoso advertir que el asunto de su identificación práctica se torna especialmente relevante y difícil. Así sucede, sobre todo, en los ordenamientos que en atención a estos conceptos jurídicos bareman la imprudencia profesional e incluso de ello depende su diferenciación de la imprudencia común (v.gr., España, Chile, Francia e Italia). Situación que se agudiza si tenemos 
en cuenta que los pronunciamientos en la doctrina penal sobre los criterios para establecer la graduación no son pacíficos. En este sentido, el propio Roxin señala que "está poco claro cuándo hay que apreciar en concreto una temeridad" (1997, p. 1024). Además, en los códigos no se establecen reglas que sirvan para modular en esta dirección la imprudencia, conminándose a los tribunales - por vía interpretativa en el ámbito de lo valorativo y axiológico- a actuar con cierto relativismo en atención al caso concreto y circunstancias concurrentes (Ventas Sastre, 2003, p. 119).

Obviamente, esto ha de redundar en una sensación de inseguridad jurídica que no beneficia ni a los pacientes ni a los profesionales de la salud. En España, v.gr., la imprudencia profesional es una modalidad agravada de la imprudencia grave (Benítez Ortúzar y Cruz Blanca, 2009, p. 167) (antes temeraria), que figura junto a aquella y la menos grave. Sardinero, refiriéndose a la incorporación de la categoría de la imprudencia menos grave en la legislación penal española con la reforma que introduce la ley orgánica $1 / 2015$ de 30 de marzo, expresó: “(...) la reforma ofrece una nueva y más que difícil distinción entre imprudencia grave, menos grave y leve, casi nada" (Sardinero García, 2015, p. 285).

Al buscar la solución en la doctrina a esta problemática, siguiendo la sistematización realizada por Roxin, advertimos que unos autores vinculan la gravedad de la imprudencia al "grave descuido o frívola falta de consideración por lo que no se tiene en cuenta la posibilidad claramente advertida de realización del tipo"; otros, cuando por "especial negligencia o ligereza o por especial indiferencia se hace caso omiso de la posibilidad que le salta a la vista de un desenlace mortal"; o bien, si se "descuida muy gravemente el empleo de las facultades intelectuales o infringe una posición de deber elevada o intensificada que le atañe objetivamente, pero sobre todo en el caso de alta probabilidad de producción del daño"; también se arguye que "depende de la valoración social de la conducta generadora de riesgo y del valor del bien jurídico amenazado" (Roxin, 1997, p. 1025 y ss.).

Bacigalupo sugiere un enfoque preventivo especial en el que se tenga en cuenta el grado de desinterés revelado por el autor respecto de los bienes ajenos. Al mismo tiempo, expresó: "De esta forma no se alcanzará un concepto preciso, pero, al menos, podrá situarse la cuestión en el lugar que le corresponde sistemáticamente" (Bacigalupo, 1999, p. 347).

En este debate asumimos la opinión del maestro germano cuando señala: "Lo correcto es considerar la temeridad como un elemento atinente al injusto y a la culpabilidad" (Roxin, 1997, p. 1026). En efecto, su concreción igualmente depende de la valoración social de la conducta generadora de riesgo y del valor del bien jurídico amenazado. Lo primero responde a la "ponderación de utilidad y riesgo", en tanto el segundo análisis conmina a que "cuando estén amenazadas vidas 
humanas se ha de afirmar antes la temeridad que cuando se trate de bienes patrimoniales limitados". En esa misma línea de pensamiento, utilizando los mismos baremos, pero en sentido inverso, procede la verificación de la imprudencia insignificante (Roxin, 1997, pp. 1010-1028).

Sea como fuere, la terea es ardua, la línea divisoria es difícil de determinar y conlleva como peligro inherente la posibilidad de incurrir en soluciones jurisprudenciales arbitrarias o contradictorias. De ahí la necesidad de que se analicen de forma exhaustiva todos los condicionamientos y circunstancias concurrentes en el supuesto enjuiciado (Sardinero García, 2015, pp. 285, 288 y 293; Ventas Sastre, 2003, p. 119). Asimismo, que los jueces "no pequen de una excesiva sobriedad al narrar o describir lo sucedido, sino que en el factum de sus sentencias no regateen ni escatimen datos o pormenores sino que lo redacten minuciosamente y con toda prolijidad posible, facilitando, de ese modo, y haciendo fundada y comprensible la delimitación, así como la calificación más certera y atinada" (extracto de la sentencia de la Sala Segunda del TS de España de fecha 22 de abril de 1988, como se citó en Ventas Sastre, 2003, p. 122).

La graduación de la imprudencia tendrá que hacerse atendiendo al contenido del desvalor de la acción, no del resultado que produzca, teniendo en cuenta las circunstancias del caso concreto. Como, por lo general, los códigos no contemplan parámetros de orientación, los extremos que deberá tener presente el juez son: la importancia de los bienes afectados, la utilidad social de la conducta, la proporción estadística entre la acción realizada y el resultado producido, el grado de previsibilidad del riesgo, conocimientos y capacidades del autor, todo ello conjugado con la relatividad de la ciencia médica y con las circunstancias de tiempo, lugar, urgencia con que se practica el acto médico (Gómez Rivero, 2003, p. 337; Sanz Mulas, 2017, pp. 317-320).

Superado este inconveniente, aun encontraremos en algunos ordenamientos referencia a las especies o formas clásicas de la impericia, negligencia e imprudencia para regular la misma categoría dogmática. Entonces, surgen algunas interrogantes: ¿ Resulta factible distinguir entre ellas como formas de imprudencia merecedoras de diferentes tratos sancionadores?, ¿La mala praxis médica penalmente relevante es solo impericia o también negligencia o imprudencia?

En términos generales, la negligencia consiste en no hacer lo que debería ser hecho, la imprudencia en hacer lo que no debería ser hecho, y la impericia en hacer mal lo que debería hacerse bien (Martínez Murillo y Saldívar, s./f., p. 36; Organización Panamericana de la Salud, 2004, p. 48; Vargas Alvarado, 2012, p. 498). En la búsqueda de la respuesta a la necesidad o no de la distinción en sede normativa, resulta de gran utilidad la valoración de la experiencia española e italiana. En esta última, v.gr., el término impericia define la aplicación o no de un régimen más 
favorable que prevé, según el caso, la exclusión de la relevancia penal de la imprudencia. Ello es expresión de una opción político-criminal que fundamentan en las mayores dificultades relacionadas con el ejercicio de la profesión y la necesidad de hacer frente al fenómeno de la medicina defensiva. En España, en cambio, sustentados en cuestiones de prevención general y especial, la misma categoría se emplea para calificar los casos de imprudencia profesional (figura agravada de la imprudencia grave) (Perin, 2018, p. 884); así lo pone de manifiesto el Tribunal Supremo a través de varias sentencias (10).

Como se aprecia, las razones y las finalidades que conllevan en uno y en otro contexto a acudir al concepto de impericia son distintas, pero, en ambos casos, su empleo ha generado un estado de incertidumbre. En España, la imprudencia profesional obedece esencialmente a supuestos de ignorancia que quedan excluidos del régimen más favorable; en Italia, la incertidumbre se manifiesta en el riesgo de que se puedan convertir supuestos de impericia (sujeta, en ciertos casos, a un régimen más favorable) en imputaciones por negligencia e imprudencia penalmente relevantes (Perin, 2018, pp. 884-885).

Para evitar los señalados inconvenientes consideramos que la impericia no es otra cosa que una imprudencia o una negligencia según la regla técnica inobservada prescriba abstenerse de cierta conducta que el sujeto realiza o bien la omisión de aquella que resulta aconsejada (Gómez Pavón, 2004, p. 341; Perin, 2018, p. 885). En fin, la relatividad de la distinción conceptual entre negligencia, imprudencia e impericia no debiera poseer gran relevancia al extremo de fundamentar la discriminación teórica o normativa entre imprudencia profesional y genérica. Mucho menos justificar una diferenciación insostenible de formas de imprudencia merecedoras de distintos tratos sancionadores. A favor de este planteamiento, Zaffaroni, Alagia y Slokar manifiestan: "la imprudencia, la negligencia y la impericia, se trata de las formas clásicas del derecho romano que, en rigor, pueden reconducirse a las dos primeras, sosteniendo algunos autores que ambas son también reconducibles recíprocamente" (Zaffaroni y otros, 2005, p. 425). No es por ello de extrañar que estos términos hayan sido eliminados de la legislación penal española con la adopción del Código Penal de 1995.

Igual objeción se impone formular a aquellos textos penales cuando junto a estas formas mencionan la "inobservancia de los deberes o reglamentos". En primer

(10) "Hay que distinguir entre la culpa del profesional, que es imprudencia o negligencia comunes cometidas por el mismo en el ejercicio de la profesión, y la culpa profesional, que es la impericia, ineptitud o ignorancia, es decir, la falta de los conocimientos básicos y elementales propios de su técnica o ciencia (...) (TS, $2^{\text {a }}$ s 21 Junio 1.974,RJ 2918) (...) la culpa profesional descansa en la impericia, en la ignorancia, al ejecutar un acto profesional, de las exigencias de la lex artis (TS $2^{\text {a }} 21$ de febrero 1986, RJ 1986, 910)", como se citó en Gutiérrez Aranguren, s./f., p. 399. 
lugar, porque la infracción a normas jurídicas que persiguen la evitación del resultado como realización de un foco de peligro puede estar asociada lo mismo a una conducta negligente, imperita o imprudente en los términos en que se han definido. En segundo lugar, como señalan Zaffaroni, Alagia y Slokar, esta inclusión resuelve muy poco, "porque existen múltiples actividades no reglamentadas y, además, porque no cualquier infracción reglamentaria implica una violación al deber de cuidado como presupuesto esencial de la imprudencia" (Zaffaroni y otros, 2005, p. 428).

\section{Reflexiones finales}

Responder por los resultados lesivos ocasionados durante el ejercicio profesional se revela como un componente ineludible de la vida social que ha experimentado extraordinario auge en la sociedad contemporánea. Entre las diversas profesiones, una de las que mayor preocupación suscita es la médica, por su directa relación con los bienes jurídicos más preciados del ser humano. Errores y mala praxis que en otros sectores de actividad tal vez no trascienden el ámbito disciplinario, constituyen para el médico una fuente cada vez más pletórica de procesos judiciales que pueden terminar con la inhabilitación profesional y la privación de libertad. En cualquier caso, es indudable que el tema de la imprudencia en el que se subsume la mala praxis médica ha resultado extremadamente polémico y adquiere tintes especiales en la "sociedad de riesgos" hoy "sociedad del riesgo regulado". Determinar cuando la conducta de un profesional de la salud ha sido imprudente con relevancia penal entraña muchas dificultades, tanto dogmáticas como de prueba.

Me doy cuenta que dejo innumerables puntos polémicos alrededor del tema. El vasto territorio de lo que es controvertido y de lo que es opinable, que aquí se presenta en toda su magnitud, constituye un intento para motivar el debate y con él la controversia, toda vez que el pensamiento creativo es el pensamiento divergente. No obstante, llamo la atención en que cualquier propuesta asociada a la responsabilidad médica debe dirigirse a conjugar, por una parte, la protección de los derechos de los pacientes y, por otra, el respeto a la probidad de los galenos, así como la promoción de mejores condiciones para su ejercicio profesional. En tal sentido, se impone que los cambios que asume el derecho penal en la sociedad contemporánea y que, de forma evidente, nos crean zonas polémicas en los predios de la dogmática, no sean asumidos por los ordenamientos jurídicos sin la realización de profundas reflexiones.

\section{Bibliografía}

Amores Agulla, T. y Marrero Quesada, J. A. (2015). Mala praxis médica en el quirófano. Revista Cubana de Cirugía, No 54 (2) (pp. 187-194). 
Bacigalupo, E. (1999). Derecho penal, parte general (2a edición totalmente renovada y ampliada). Argentina: Editorial Hammurabi SRL.

Benítez Ortúzar, I. y Cruz Blanca, M. (2009). La imprudencia punible en el ámbito de la actividad médico-quirúrgica. En J. M. Suárez López y L. Morillas Cueva, Estudios Jurídicos sobre responsabilidad penal, civil y administrativa del médico y otros agentes sanitarios (pp. 155-199). Madrid: Dykinson.

Bustos Ramírez, J. J. y Hormazábal Malarée, H. (1997). Lecciones de derecho penal, vol. I. Madrid: Editorial Trotta.

Cadavid Quintero, A. (1998). La imprudencia profesional en el Código de 1995. En V. Sánchez López (coord.), Nuevas Cuestiones Penales (pp. 75-96). Madrid: Colex.

Córdoba Roda, J. (1996). Configuración de la imprudencia en el ámbito sanitario en el nuevo Código penal. Der. Sad, 2 (pp. 140-146).

David Tole, H. y Cadavid, N. (2018). Instrumentador quirúrgico: iatrogenia, eventos frecuentes y responsabilidad en el quirófano. Repertorio de Medicina y Cirugía, 27(2) (pp. 124-130).

De Larrañaga Monjaraz, P. (1996). El concepto de responsabilidad en la teoría del derecho contemporánea (Tesis doctoral). Universidad de Alicante, España. Recuperado de http://rua.ua.es/dspace/bitstream/10045/6709/1/Larra\%c3\%blagaMonjaraz-Pablo-de.pdf; http://hdl.handle.net/10045/6709

De Larrañaga Monjaraz, P. (2015). La responsabilidad en el derecho: Una aproximación sistémica. Enciclopedia de Filosofía y Teoría del Derecho, vol. 2 (pp. 1455-1478). México: IIJ-UNAM.

De Vicente Remesal, J. (2000). Criterios jurisprudenciales sobre la imprudencia profesional en el ámbito médico sanitario. Controversia. Revista Xurídica Xeral, Segunda época (1) (pp. 91-113).

De Vicente Remesal, J. y Rodríguez Vázquez, V. (2007). El médico ante el Derecho penal: consideraciones sobre la imprudencia profesional, inhabilitación profesional y el trabajo en equipo. En F. Pérez Álvarez (Ed.), Universitas vitae. Homenaje a Ruperto Núñez Barbero (pp. 145-178). Salamanca: Ediciones Universidad de Salamanca.

Díez Ripolles, J.; Gracia Martín, L. y Laurenzo Copello, P. (1997). Comentarios al Código penal. Parte especial, vol. I. Valencia: Tirant lo Blanch. 
Dossier: Mala praxis médica. Selección de jurisprudencia y doctrina (2018). Ministerio de Justicia y Derechos Humanos. Sistema Argentino de Información Jurídica. Recuperado de http://www.saij.gob.ar/docs-f/dossier-f/mala_praxis_ medica.pdf

Fernández Hierro, J. (1997). Sistema de responsabilidad médica. Granada: Comares.

Ferrajoli, L. (1997). Expectativas y garantías. Primeras tesis de una teoría axiomatizada del Derecho. DOXA, 20 (pp. 235-278).

Figueroa Rubio, S. y Torres Ortega, I. C. (2018). Dos tesis de H. L. A. Hart sobre responsabilidad y castigo: 50 años después. Derecho PUCP, 81 (pp. 9-46). Recuperado de https://doi.org/https://doi.org/10.18800/derechopucp.201802.001

Franco, P. (2019). 2019, el año con mayor cantidad de actos procesales en contra de los médicos en Ecuador [Redacción Médica]. Recuperado de https://www. redaccionmedica.ec/secciones/profesionales/2019-el-ano-con-mayor-cantidadde-actos-procesales-en-contra-de-los-medicos-en-ecuador--valer-94214

Gamboa Montejano, C. y Valdés Robledo, S. (2015). Responsabilidad de los profesionales de la salud. Marco Teórico Conceptual, Marco Jurídico, Instrumentos Internacionales, Jurisprudencia (Primera Parte) (No. SAPI-ISS-79-15). México: Cámara de Diputados LXIII Legislatura. Dirección General de Servicios de Documentación, Información y Análisis. Recuperado de http://www.diputados.gob. $\mathrm{mx} /$ sedia/sia/spi/SAPI-ISS-79-15.pdf

García Andrade, J. (1998). Reflexiones sobre la responsabilidad médica. Madrid: Edersa.

García Rivas, N. (1999). La imprudencia "profesional": una especie a extinguir. RDSoc, 6 (pp. 79-96).

Gómez Pavón, P. (2004). Tratamientos médicos: su responsabilidad penal y civil, 2da ed. España: Bosch.

Gómez Rivero, M. del C. (2003). La responsabilidad penal del médico. Valencia: Tirant lo Blanch.

Gratascós Gómez, N. (1997). La imprudencia en el nuevo Código penal. Especial referencia de la imprudencia profesional y la inhabilitación especial para el ejercicio de una profesión, oficio o cargo. Der.Sad, 1 (pp. 62-75). 
Gutiérrez Aranguren, J. L. (s./f.). La imprudencia profesional. Lecciones de Derecho Sanitario (pp. 391-407). Recuperado de http://ruc.udc.es/dspace/bitstream/ handle/2183/10747/CC\%2047\%20art\%2017.pdf?sequence=1

Guzmán Mejía, J. I. (2018). Ante la mala praxis quirúrgica, ¿trascendencia ética o legal? Cirujano General, 40 (1) (pp. 46-53).

Hava García, E. (2001). La imprudencia médica. Valencia: Tirant lo Blanch.

Hava García, E. (2002). La imprudencia inconsciente. Granada: Comares.

Jescheck, H. H. y Weigend, T. (2002). Tratado de Derecho Penal. Parte General (M. Olmedo Cardenete, Trad.) (5ta edición, renovada y ampliada). Granada: Colmares.

Koudriavtsev, V. (1988). Derechos del individuo en la sociedad socialista. Moscú: Naoka.

Martínez de Navarrete, A. (1995). Diccionario jurídico básico. Buenos Aires, Argentina: Editorial Heliasta S.R.L.

Martínez Lazcano, M. (2011). La graduación del deber de cuidado en el delito culposo por actos de mala praxis médica: un análisis dogmático, jurisprudencial y económico. Polít. crim., 6 (12) (pp. 214-251).

Martínez Murillo, S. y Saldívar, S. L. (s./f.). Medicina Legal, 17a edición. México, Distrito Federal: Méndez Editores.

Martínez Pérez, O. y Alzate Peralta, L. A. (2019). La responsabilidad legal de los profesionales de la salud: retos y desafíos. Identidad Bolivariana, 3 (2) (pp. 1-21).

Méndez López, M. B. (2009). La responsabilidad civil derivada del delito de las personas naturales (Tesis doctoral). Universidad de Oriente, Santiago de Cuba.

Méndez López, M. B. y Goite Pierre, M. (2012). La responsabilidad civil derivada del delito de las personas naturales en Cuba. En M. Goyte Pierre (coord.), Las consecuencias jurídicas derivadas del delito y una mirada a la persona jurídica desde Cuba y España (pp. 173-276). Valencia: Tirant lo Blanch.

Ministerio de Salud Pública del Ecuador. (s./f.). MSP explica el art 146 del COIP. Recuperado de https://www.salud.gob.ec/msp-explica-el-art-146-del-coip/

Mir Puig, S. (2016). Derecho Penal Parte General, 10a edición actualizada y revisada. Barcelona: Editorial Reppertor. 
Molina Fernández, F. (2000). Presupuestos de responsabilidad jurídica (análisis de la relación entre libertad y responsabilidad). Anuario de Derecho Penal y Ciencias Penales. Ministerio de Justicia (Centro de Publicaciones) y Boletín Oficial del Estado, LIII (pp. 167-283).

Muñoz Conde, F. y García Arán, M. (2010). Derecho Penal Parte General, 8a edición. Valencia: Tirant lo Blanch.

Nino, C. S. (2003). Introducción al análisis del derecho, $2^{\mathrm{a}}$ ed. ampliada y revisada. Buenos Aires: Editorial Astrea.

Núñez Barbero, R. (1975). El delito culposo (su estructuración jurídica en la dogmática actual). Salamanca: Universidad de Salamanca.

Organización Panamericana de la Salud. (2004). Aspectos de medicina legal en la práctica diaria: guía para profesionales de servicios públicos de salud. La Paz: OPS/OMS.

Palencia Núñez, M. R. I. (2017). Presupuestos para el redimensionamiento teórico del deber objetivo de cuidado en Ecuador (Tesis doctoral). La Habana: Universidad de La Habana.

Perin, A. (2018). La redefinición de la culpa (imprudencia) penal médica ante el fenómeno de la medicina defensiva. Bases desde una perspectiva comparada. Polit. crim., 13 (26) (pp. 858-903).

Quirós Pírez, R. (2002). Manual de Derecho Penal, vol. III. La Habana: Félix Varela.

Rodríguez Vázquez, V. (2012). Responsabilidad penal en el ejercicio de actividades médico-sanitarias. Criterios para delimitar la responsabilidad en supuestos de intervención conjunta de los profesionales sanitarios. Madrid: Marcial Pons.

Romeo Casabona, C. M. (2005). Conducta peligrosa e imprudencia en la sociedad de riesgo. Granada: Comares.

Romeo Casabona, C. M. (2007). Evolución del tratamiento jurídico-penal de la imprudencia del personal médico-sanitario. Revista Jurídica de Castilla y León, 13 (pp. 211-251).

Roxin, C. (1997). Derecho Penal Parte General. Fundamentos. La estructura de la teoría del delito (D.-M. Luzón Peña, M. D. y García Conlledo, \& J. De Vicente Remesal, Trads.), 2da ed., vol. I. España: Civitas, S. A. 
Ruíz Vadillo, E. (1994). La responsabilidad civil y penal de los profesionales de la medicina. Actualidad Penal, No 27 (pp. 499-519).

Sanz Mulas, N. (2014). La responsabilidad penal del personal. En E. Llamas Pombo (dir.), Estudios sobre responsabilidad sanitaria. Un análisis interdisciplinar (pp. 291-340). Madrid: La Ley.

Sanz Mulas, N. (2017). Despilfarro de fondos públicos y nuevo delito de malversación de caudales. Revista Electrónica de Ciencia Penal y Criminología, 19-05 (pp. 1-35).

Sardinero García, C. (2015). La imprudencia profesional ante la profunda reforma del Código Penal. Actualidad del Derecho Sanitario, 226 (pp. 283-293).

Schünemann, B. (1975). Modernas tendencias en la dogmática de los delitos imprudentes y de peligro. Juristische Arbeitsblätter.

Silva Sánchez, J. M. (1999). Medicinas alternativas e imprudencia médica. Barcelona: José María Bosch Editor.

Terragni, M. A. (2001). La moderna teoría de la imputación objetiva y la negligencia punible. Conferencia pronunciada en las Jornadas Internacionales de Derecho Penal en Homenaje al Dr. Claus Roxin, en la Ciudad de Córdoba (Argentina). Recuperado de https://www.scribd.com/document/144969274/La-ModernaTeoria-de-La-Imputacion-Objetiva-y-La-Negligencia-Medica-Punible-Terragni

Terragni, M. A. (2003). El delito culposo. Santa Fe: Rubinzal-Culzoni.

Valdés Díaz, C. del C. (2005). La relación jurídica civil. En C. C. Valdez Díaz (coord.), Derecho Civil Parte General (pp. 77-100). La Habana: Editorial Félix Varela.

Vallejo Jiménez, G. A. (2012). Responsabilidad penal sanitaria: problemas específicos en torno a la imprudencia médica (Tesis doctoral). León: Universidad de León. Recuperado de https://buleria.unileon.es/bitstream/handle/10612/2217/ tesis_e4242b.pdf?sequence $=1$

Vargas Alvarado, E. (2012). Medicina legal, 4ta ed. México: Editorial Trillas.

Ventas Sastre, R. (2003). Tratamiento jurídico-penal de las imprudencias sanitarias con resultado de muerte o lesiones en el derecho español. Recuperado de http://www.usfq.edu.ec/publicaciones/iurisDictio/archivo_de_contenidos/Documents/IurisDictio_10/Tratamiento_juridico_penal_de_las_imprudencias_sanitarias_con_resultado_de_muerte.pdf 
Vila Morales, D. y Pérez Echeverría, R. (2013). Responsabilidad médica en el derecho médico cubano y otros países. En D. Vila Morales, Teoría del derecho médico (pp. 184-242). La Habana: Ciencias Médicas.

Villacampa Estiarte, C. (2003). Responsabilidad penal del personal sanitario. Atribución de responsabilidad penal en tratamientos médicos efectuados por diversos profesionales. Pamplona: Aranzadi.

Vodanovic, A. (1995). Manual de Derecho Civil, vol. I. Santiago de Chile: Editorial H. T.

Welzel, H. (2004). El nuevo sistema del derecho Penal. Una introducción a la doctrina de la acción finalista (J. Cerezo Mir, Trad.) (Segunda reimpresión). Buenos Aires: B de F Ltda.

Zaffaroni, E. R.; Alagia, A. y Slokar, A. (2005). Manual de Derecho Penal: Parte General, 1ra edición. Buenos Aires: Ediar.

\section{Legislación}

Ley 11.179, Código Penal Argentino.

Código Penal de Chile, 1/06/74, modificado por la ley No 20.074 de 2005.

Código Penal de Colombia, ley No 600, 24/07/00.

Código penal de España, Ley orgánica 10/1995, Edición actualizada a 28 de julio de 2020. BOE No 281, 24/11/95. Última modificación: 2 de marzo de 2019.

Código Penal de la República Bolivariana de Venezuela, Gaceta Oficial No 5494 Extraordinario, 20/10/00.

Código Penal de la República de Costa Rica: de 14 de abril de 1998. Consultado en https://www.oas.org/dil/esp/Codigo-Penal-Costa-Rica.pdf en fecha $28 \mathrm{de}$ enero de 2018.

Código Penal de la República de Francia, última modificación 15/09/03.

Código Penal de la República de Italia, aprobado por LO 10/1995.

Código Penal de la República del Salvador, decreto No 1030, 26/04/97.

Código Penal de la República Federal Alemania, 15/04/71.

Código Penal de la República Oriental del Uruguay, aprobado por ley 9.155. Recuperado de http://www.minterior.gub.uy/indices/index_comet.htm 
Código Penal de los Estados Unidos mexicanos, 14/08/31, última reforma 23 de agosto de 2005.

Código Penal de Paraguay, aprobado por ley № 1160/97. Recuperado de https://www.oas.org/dil/esp/Codigo_Penal_Paraguay.pdf

Código Penal del Estado Plurinacional de Bolivia, Decreto Supremo № 0667.

Código Penal y Código de Procedimiento Penal de Bolivia, ley No 1768, 10/03/97). Recuperado de

http://www.unodc.org/res/cld/document/bol/codigo-penal_html/Bolivia_ Codigo_Penal.pdf

Código Orgánico Integral Penal, República de Ecuador, Registro Oficial No 180, 10/08/14. Recuperado de http://www.ecu911.gob.ec/TransparenciaArchivo/ ENERO2015/Anexos\%20a2/C\%C3\%93DIGO\%20ORGANICO\%20INTEGRAL\%20 PENAL.pdf

Fecha de recepción: 30-03-2020

Fecha de aceptación: 28-06-2020 
